ACESSIBILIDADE NO ENSINO PROFISSIONAL TECNOLOGICO: UMA DESCRIÇÃO DAS AÇÕES DE INCLUSÃO.

\author{
ACCESSIBILITY IN TEACHING PROFESSIONAL \\ TECHNOLOGICAL: A DESCRIPTION OF INCLUSION OF SHARES.
}

DOI: http://dx.doi.org/105965198431781212016026

Kelma Freitas Felipe - IFCE

\title{
RESUMO
}

O presente trabalho elenca as ações de inclusão desenvolvida pelo Núcleo de Acessibilidade às Pessoas com Necessidades Educacionais Específicas (NAPNE) do Instituto Federal de Educação, Ciência e Tecnologia (IFCE) - Campus Limoeiro do Norte, no período de março de 2014 a março de 2015. Neste estudo utilizou-se a pesquisa qualiquatitativa para descrição e análise das ações realizadas durante um (01) ano, em busca da inclusão de pessoas com deficiência (PcD) no espaço educacional. Foram objetos de estudo: 1) Palestras e Oficinas sobre Educação Inclusiva; 2) Elaboração de tutorial com orientações e adaptações didática-pedagógica; 3) Projeto Monitoria Inclusiva, 4) Relatório de acessibilidade arquitetônica no IFCE-campus Limoeiro do Norte. Como resultado verificou-se que tomar posse de informações sobre esta temática e difundi-las possibilita uma compreensão da política de inclusão, de seus entraves e limites dentro do espaço educacional, além de permitir uma maior interação entre servidores, discentes e sociedade civil na busca pela inclusão social e acessibilidade da PcD. Na pesquisa também se concluiu que o referido ano foi um marco para a ampliação das discussões sobre a Educação Inclusiva no campus, o que oportunizou o desenvolvimento de estratégias de acessibilidade, além de colaborar com a permanência dos discentes na instituição, considerando que do total de 06 alunos matriculados apenas 01 evadiu.

PALAVRAS-CHAVE: educação inclusiva, educação profissional e tecnológica, acessibilidade.

\begin{abstract}
This paper lists the inclusion of actions developed by the Accessibility Center for People with Special Educational Needs (NAPNE) of the Federal Institute of Education, Science and Technology (IFCE) - Campus Limoeiro do Norte, in the year 2014. This study used the quali-quatitativa search for description and analysis of the actions taken for one (01) year, seeking the inclusion of people with disabilities (DP) in the educational space. They were objects of study: 1) Lectures and workshops on Inclusive Education; 2) Preparation of tutorial with guidance and didactic-pedagogic adaptations; 3) Project Monitoring Inclusive, 4) architectural accessibility Report on IFCE-campus North Limoeiro. As a result it was found that taking possession of information on this subject and circulate it enables an understanding of the politics of inclusion, its barriers and boundaries within the educational space, and allow greater interaction between servers, students and civil society in the search for social inclusion and accessibility of DP. In the survey also found that that year was a milestone for the expansion of discussions on Inclusive Education on campus, which provided an opportunity to develop accessibility strategies, as well as collaborating with the permanence of students in the institution, whereas the total 06 students enrolled only 01 escaped.
\end{abstract}

KEYWORDS: inclusive education, professional education and technology, accessibility. 


\section{EDUCAÇÃO, ARTES E INCLUSÃO}

\section{INTRODUÇÃO}

Trabalhar a inclusão social da Pessoa com Deficiência $(\mathrm{PcD})$ vem ao longo das décadas se tornando uma temática em destaque na busca pela ampliação e consolidação dos direitos.

Em 2009, o Brasil ratificou a Convenção sobre os Direitos das Pessoas com Deficiência, adotada pela Organização das Nações Unidas (ONU), e com isso incentivou a garantia de acesso, direitos e deveres no espaço social a todas as pessoas que apresentam/possuem alguma tipo de deficiência.

Segundo dados do Instituto Brasileiro de Geografia e Estatística (IBGE, 2010), $23 \%$ do total da população brasileira, isto é 45.606 .048 pessoas, têm algum tipo de deficiência (aqui estão as pessoas que se classificam com deficiência e aquelas com limitações funcionais) sendo que visual são 18,60\%; auditiva, 5,10\%; motora, $7 \%$ e intelectual, $1,40 \%$.

Se analisarmos este dado por região no Brasil tem-se: Sul: 22,50\%; Centro-oeste: 22,51\%; Sudeste 23,03\%; Norte: $23,40 \%$ e Nordeste: $26,63 \%$, sendo a região do Nordeste aquela que apresenta maior porcentagem. Entre os estados brasileiros, a maior incidência da deficiência ocorreu nos estados do Rio Grande do Norte, da Paraíba e do Ceará com taxas, respectivamente, de $27,76 \%, 27,58 \%$ e $27,69 \%$ (IBGE, 2010).

Em Limoeiro do Norte, município do estado do Ceará onde foi realizado o estudo, do total de 56.264 habitantes, 20.337 declararam apresentar alguma deficiência, conforme descrito na Tabela 01 .

\begin{tabular}{c|c}
\hline Descrição da Deficiência & Qtd. \\
\hline População residente com deficiência visual - não consegue de modo algum & 184 \\
População residente com deficiência visual - grande dificuldade & 2.277 \\
População residente com deficiência visual - alguma dificuldade & 9.739 \\
População residente com deficiência auditiva - não consegue de modo algum & 87 \\
População residente com deficiência auditiva - grande dificuldade & 636 \\
População residente com deficiência auditiva - alguma dificuldade & 2.908 \\
População residente com deficiência motora - não consegue de modo algum & 251 \\
População residente com deficiência motora - grande dificuldade & 997 \\
População residente com deficiência motora - alguma dificuldade & 2.616 \\
População residente com mental/intelectual & 642 \\
\hline Total & 20.337 \\
\hline
\end{tabular}

Tabela 01: $\mathrm{N}^{\circ}$ de pessoas com deficiência no município de Limoeiro do Norte-CE. Fonte: Dados do IBGE (2010) 
Em relação à qualificação profissional e inserção no mercado de trabalho, segundo os dados do IBGE (2010), a frequência de PcD ocupadas sem escolaridade $(10,7 \%)$ era mais de 3 vezes superior à das pessoas sem deficiência ou limitação funcional, enquanto que a frequência de $\mathrm{PcD}$ com nível superior completo ou incompleto $(10,3 \%)$ era duas vezes inferior à das pessoas sem deficiência ou limitação funcional.

Considerando as lutas travadas para dar visibilidade a este grupo de pessoas que mesmo apresentando alguma deficiência também são sujeitos de direitos, assim definidos na Constituição de 88, dentre outras legislações, o Instituto Federal de Educação, Ciência e Tecnologia iniciou ações voltadas para a Educação Inclusiva através do Programa TEC NEP - Educação, Tecnologia e Profisssionalização para Pessoas com Necessidades Educacionais Específicas, instituído pelo MEC/SETEC-SEESP (BRASIL, 2011).

A partir deste programa, o IFCE implantou em seus campi os Núcleos de Acessibilidade às Pessoas com Necessidades Educacionais Específicas - NAPNE com o objetivo de criar na instituição a cultura da "educação para a convivência", a aceitação da diversidade, a eliminação de barreiras arquitetônicas, educacionais e atitudinais, incluindo socialmente a todos através da educação.

No IFCE-campus Limoeiro do Norte, o NAPNE foi instituído pela portaria de $\mathrm{n}^{\mathrm{o}}$ 14/GDG, no dia 15 de junho de 2012. Atualmente, é composto por uma equipe interdisciplinar com a participação de Assistente Social, Docente, Intérprete em Libras, Pedagoga e Veterinária. Dentre as atribuições a serem desenvolvidas tem-se: análise de barreiras arquitetônicas, educacionais e atitudinais; realização de atendimento e acompanhamento de pessoas com necessidades educacionais específicas no campus; promoção de eventos que envolvam a sensibilização e capacitação de servidores e comunidade em geral; aquisição de equipamentos, software e material didáticopedagógico; e, orientações sobre adaptações curriculares e/ou didáticas pedagógicas.

O objetivo geral deste estudo é averiguar as ações de acessibilidade desenvolvidas pelo NAPNE no IFCE-campus Limoeiro do Norte, para o ingresso, a permanência e o êxito de discentes com deficiência.

Referente aos fatores que levaram a escolha deste campo de pesquisa pode-se destacar à inserção da pesquisadora no NAPNE do referido campus, participando e observando das atividades de sensibilização para a Educação Inclusiva. Além disso, verificar in loco a inserção de $\mathrm{PcD}$ no espaço educacional despertou a necessidade de 


\section{EDUCAÇÃO, ARTES E INCLUSÃO}

\section{5}

melhor compreender a política de educação inclusiva assim como as dificuldades e avanços vivenciados nas experiências realizadas.

\section{ENTENDENDO O PROCESSO DE INCLUSÃO DE PESSOAS COM DEFICIÊNCIA.}

Historicamente, a Pessoa com Deficiência $(\mathrm{PcD})$ foi excluída em vários períodos da nossa sociedade humana, sendo esse processo de exclusão decorrente de concepções vividas, de períodos históricos e da cultura dos povos.

Na Antiguidade a Pessoa com Deficiência $(\mathrm{PcD})$ era considerada anormal, pois havia uma supervalorização da perfeição do corpo e o ser humano com deformidades trariam implicações negativas nas vitórias durante as guerras. Com o advento do Cristianismo, Idade Média, a igreja começou a combater a prática de eliminação das crianças nascidas com deficiência, surgindo os primeiros hospitais de caridade. Na Idade Moderna, a ciência renascentista buscou explicações para a deficiência do homem. E, com a Revolução Industrial iniciada no século XVIII a questão da habilitação e da reabilitação da Pessoa com Deficiência para o trabalho ganhou destaque (VIEIRA, 2013).

No Brasil, somente a partir da Revolução Industrial iniciada no século XVIII iniciou-se uma preocupação do Estado em relação à $\mathrm{PcD}$, na busca de promover a questão da habilitação e da reabilitação para o trabalho por considerar o grande índice de acidentes que mutilavam trabalhadores nas indústrias devido às precárias condições de trabalho (MAZZOTTA, 2005).

Diante desta situação, foram criadas algumas instituições no Brasil que objetivava a reabilitação associada à redução de custo do Estado por possibilitar aos mutilados a volta ao mercado de trabalho.

Uma das primeiras instituições criadas no Brasil foi o Imperial Instituto dos Meninos Cegos, no Rio de Janeiro, o qual passou a ser nomeado como Instituto Benjamin Constant em 1890. Com este instituto a questão da deficiência deixou de ser responsabilidade única da família e passou a ser um "problema” do Estado. Em 1857 também se fundou o Imperial Instituto dos Surdos-Mudos também no Rio de Janeiro, e cem anos após sua fundação passou a ser dominado como Instituto Nacional de Educação de Surdos-INES (MAZZOTTA, 2005). 


\section{EDUCAÇÃO, ARTES E INCLUSÃO}

Estas instituições, mesmo que sobre uma perspectiva de atendimento terapêutico (modelo médico ${ }^{1}$ ), possibilitaram, nos anos 1960 (Séc. XX), que profissionais despertassem para a necessidade de escolarização das pessoas com deficiência sendo institucionalizada no Brasil a Educação Especial.

Diante dos avanços, em 1973, o Ministério da Educação criou o Centro Nacional de Educação Especial $\left(\mathrm{CENESP}^{2}\right)$, proporcionando o planejamento de politicas públicas voltadas para PcD e estimulando o aperfeiçoamento de método e técnicas de ensino através do desenvolvimento acadêmico e científico na área (GLAT et al., 2011).

De acordo com Figueira (2008): "Se até aqui a Pessoa com Deficiência caminhou em silêncio, excluída ou segregada em entidades, a partir de 1981 - Ano Internacional da Pessoa Deficiente ${ }^{3}$-, tomando consciência de si, passou a se organizar politicamente". Passagem do modelo médico para o modelo social ${ }^{4}$ de reconhecimento da $\mathrm{PcD}$, fase inicial da construção do termo inclusão.

O decreto de $\mathrm{n}^{\circ} 3.298$ de 1999 definiu em seu artigo $4^{\circ}$ os seguintes conceitos em relação ao portador de deficiência (termo ainda utilizado neste período):

I - deficiência física - alteração completa ou parcial de um ou mais segmentos do corpo humano, acarretando o comprometimento da função física, apresentando-se sob a forma de paraplegia, paraparesia, monoplegia, monoparesia, tetraplegia, tetraparesia, triplegia, triparesia, hemiplegia, hemiparesia, ostomia, amputação ou ausência de membro, paralisia cerebral, nanismo, membros com deformidade congênita ou adquirida, exceto as deformidades estéticas e as que não produzam dificuldades para o desempenho de funções;

II- deficiência auditiva - perda bilateral, parcial ou total, de quarenta e um decibéis $(\mathrm{dB})$ ou mais, aferida por audiograma nas frequências de $500 \mathrm{HZ}, 1.000 \mathrm{HZ}, 2.000 \mathrm{~Hz}$ e $3.000 \mathrm{~Hz}$;

III - deficiência visual - cegueira, na qual a acuidade visual é igual ou menor que 0,05 no melhor olho, com a melhor correção óptica; a baixa visão, que significa acuidade visual entre 0,3 e 0,05 no melhor olho, com a melhor correção óptica; os casos nos quais a somatória da medida do campo visual em ambos os olhos for igual ou menor que 60o; ou a ocorrência simultânea de quaisquer das condições anteriores;

\footnotetext{
${ }^{1}$ Segundo o modelo médico da deficiência a pessoa com deficiência precisa ser curada, tratada, reabilitada, habilitada etc. a fim de ser adequada à sociedade como ela é, sem maiores modificações (SASSAKI, 1997, p. 29).

2. Em 1986 este órgão foi transformado na Secretaria de Educação Especial - SEESP e em 2011 esta secretaria foi incorporada a SECADI - Secretaria de Educação Continuada, Alfabetização, Diversidade e Inclusão (MAZZOTTA, 2011).

3. O Ano Internacional da Pessoa com Deficiência (AIPD) foi o ano da "conscientização", tendo sido organizadas várias manifestações para despertar a sociedade sobre a questão da deficiência e os direitos da Pessoa com Deficiência tendo como resultado: A Declaração de Salamanca (1994) e a Convenção sobre os Direitos das Pessoas com Deficiência (2009).

${ }^{4}$ Segundo o modelo social da deficiência as atitudes da sociedade e o nosso ambiente que necessitam mudar (SASSAKI, 1997, p. 45).
} 
IV - deficiência mental - funcionamento intelectual significativamente inferior à média, com manifestação antes dos dezoito anos e limitações associadas a duas ou mais áreas de habilidades adaptativas, tais como: a) comunicação; b) cuidado pessoal; c) habilidades sociais; d) utilização dos recursos da comunidade; e) saúde e segurança; f) habilidades acadêmicas.

Com a Constituição de 1988, definiu-se em seu artigo 208, inciso III: “atendimento educacional especializado aos portadores de deficiência, preferencialmente na rede regular de ensino", surgindo então o termo Educação Inclusiva.

De acordo com Sassaki (1997), a Educação Inclusiva surgiu nos anos 90, e tal movimento foi provocado pela Conferência Mundial de Educação para Todos, realizada em Jomtiem, Tailândia, e a Conferência Mundial de Educação Especial, realizada em Salamanca, Espanha.

Em relação à história da atenção educacional para pessoa com deficiência, Sassaki (1997) afirma que esta passou por 04 fases (exclusão, segregação institucional, integração e inclusão).

$\mathrm{Na}$ Fase de exclusão, nenhuma atenção foi fornecida às pessoas com deficiência por considerar que elas não necessitariam de uma educação escolar. Na Fase de segregação institucional, as famílias de PcD se uniram para criar escolas especiais, fazendo com que PcD passassem a ter acesso a escola porém de forma separada dos demais alunos. Na Fase de integração, crianças e jovens mais aptos eram encaminhados às escolas comuns, classes especiais e salas de recursos. Nesta fase, exige-se um esforço unilateral tão somente da pessoa com deficiência e seus aliados (a família, comunidade), sendo que a pessoa com deficiência devia tornar-se mais aceitável pela comunidade. Na Fase de inclusão, todas as pessoas sãs incluídas nas salas comuns. Nesta fase o objetivo é modificar a sociedade de acordo com as necessidades das $\mathrm{PcD}$ ao compreender que ela precisa ser capaz de atender às necessidades de seus membros. Assim, a fase da inclusão define que incluir não significa somente adaptar o indivíduo a sociedade, mas também promover na sociedade ajustes que viabilizem a inclusão destes.

Diante deste momento histórico de mudanças na sociedade, diversos instrumentos legais foram instituídos como o objetivo de legitimar a inclusão de $\mathrm{PcD}$, em especial no espaço educacional, os quais serão citados a seguir.

Em 2009, o Brasil ratificou a Convenção sobre os Direitos das Pessoas com Deficiência, adotada pela Organização das Nações Unidas (ONU), e com isso buscou garantir acesso, direitos e deveres no espaço social a todas as pessoas que possuem algum 


\section{EDUCAÇÃO, ARTES E INCLUSÃO}

tipo de deficiência. Ela permitiu o avanço na consolidação dos direitos humanos e o reconhecimento de que ainda há um longo caminho a percorrer no âmbito da inclusão de Pessoa com Deficiência.

No ano de 1996, a Lei de Diretrizes e Bases da Educação Nacional (LDB), define em seu artigo 59 que os sistemas de ensino assegurarão currículos, métodos, técnicas, recursos educativos e organizações específicas aos educandos com deficiência, transtornos globais do desenvolvimento e altas habilidades ou superdotação, assim definido pelo documento Marcos Político Legais da Educação Especial na Perspectiva da Educação Inclusiva (BRASIL, 2010):

Consideram-se alunos com deficiência àqueles que têm impedimentos de longo prazo, de natureza física, mental, intelectual ou sensorial, que em interação com diversas barreiras podem ter restringida sua participação plena e efetiva na escola e na sociedade. Os alunos com transtornos globais do desenvolvimento são aqueles que apresentam alterações qualitativas das interações sociais recíprocas e na comunicação, um repertório de interesses e atividades restrito, estereotipado e repetitivo. Incluem-se nesse grupo alunos com autismo, síndromes do espectro do autismo e psicose infantil. Alunos com altas habilidades/superdotação demonstram potencial elevado em qualquer uma das seguintes áreas, isoladas ou combinadas: intelectual, acadêmica, liderança, psicomotricidade e artes. Também apresentam elevada criatividade, grande envolvimento na aprendizagem e realização de tarefas em áreas de seu interesse (p.21).

Conforme a Política Nacional de Educação Especial na Perspectiva Inclusiva (2008), a Educação Inclusiva constitui um paradigma educacional fundamentado na concepção de direitos humanos, que conjuga igualdade e diferença como valores indissociáveis, e que avança em relação à ideia de equidade formal ao contextualizar as circunstâncias históricas da produção da exclusão dentro e fora da escola.

Para a Política Nacional de Educação Especial na Perspectiva da Educação Inclusiva:

Ao reconhecer que as dificuldades enfrentadas nos sistemas de ensino evidenciam a necessidade de confrontar as práticas discriminatórias e criar alternativas para superá-las, a educação inclusiva assume espaço central no debate acerca da sociedade contemporânea e do papel da escola na superação da lógica da exclusão (BRASIL, 2008, p. 01). 


\section{EDUCAÇÃO, ARTES E INCLUSÃO}

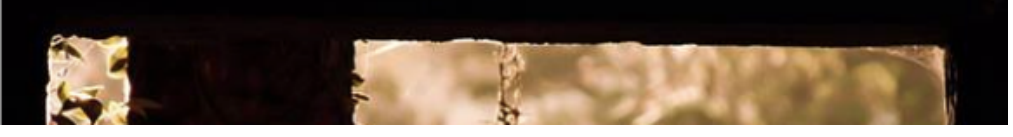

No Plano Nacional de Educação (PNE - 2014 a 2024), metas e estratégias foram estabelecidas com o objetivo de oportunizar condições que ofereçam um espaço educacional inclusivo.

O Estado abandona a postura estática, passando a desenvolver políticas públicas que favoreçam o desenvolvimento de ações afirmativas de direitos a minorias. Segundo Walter Borges dos Santos, coordenador-geral de política de acessibilidade na escola da Secretaria de Educação Continuada, Alfabetização, Diversidade e Inclusão (Secadi) do Ministério da Educação:

O número de matrículas de pessoas com deficiência em escolas regulares cresceu mais de $400 \%$ nos últimos 12 anos no Brasil, passando de 145 mil em 2003 para 698 mil em 2014. Somente no último quinquênio, foram registradas mais 214 mil entradas de estudantes especiais em classes comuns. Na rede federal de educação superior, esse índice quintuplicou: de 3.705 alunos para 19.812 no ano passado (BRASIL, 2015).

Porém, é valido ressaltar que essa forma de inserção ainda apresenta grandes restrições, pois ainda prevalece às ações de integração em detrimento a inclusão, já que os espaços educacionais não oferecem condições adequadas para a inserção deste alunado. A cultura de estigmatizar este público ainda permanece muito arraigada, fazendo-se necessárias mudanças atitudinais, pedagógicas e arquitetônicas que favoreçam a real inclusão, com mudanças nas metodologias de ensino e avaliação, adaptações curriculares, profissionais qualificados e estruturas arquitetônicas adequadas.

De acordo com o documento Normas sobre a Equiparação de Oportunidades para Pessoa com Deficiência (Nações Unidas, 1996) apud Sassaki (1997, p.138):

“1. As autoridades da educação comum são responsáveis pela educação de pessoas com deficiência em ambientes inclusivos. Elas devem garantir que a educação de pessoas com deficiência seja uma parte integrante do planejamento educacional nacional, do desenvolvimento de currículo e da organização escolar".

"2. A educação em escolas comuns pressupõe a provisão de intérprete e outros serviços de apoio adequados. Serviços adequados de acessibilidade e de apoio, projetados para atender às necessidades de pessoas com deficiência, devem ser prestados".

Se a proposta da Educação Inclusiva ainda apresenta suas fragilidades e resistências no nível de educação básica que tem como objetivo principal o aspecto 


\title{
EDUCAÇÃO, ARTES E INCLUSÃO
}

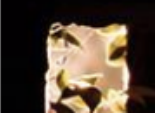

formativo do discente, na modalidade de ensino profissional e tecnológica a situação caminha a pequenos passos, pois aliado à formação educacional e humana, tem-se a formação profissional voltada para as necessidades do mundo do trabalho, espaço este competitivo, alienante, que exige um trabalhador polivalente, que esteja adaptado às necessidades do mercado, visando sempre o lucro.

Para além das necessidades impostas pelo mundo do trabalho, outro aspecto dificultador para a inclusão da PcD nos Instituto de Educação Superior (IES) é a limitação do número de vagas, por ser uma educação seletiva ao invés de universal. Somando-se a este processo de seleção existe a ausência das leis de cotas, as fragilidades educativas vividas no ensino básico, à insuficiência de profissionais qualificados e a falta de estrutura física, o que reduz as possibilidades de acesso. Conforme Manzini (2008, p. 283)

\begin{abstract}
A palavra acesso pode trazer embutida a ideia de sair de um determinado lugar ou situação e ir para lugar ou situação diferente da anterior. Esse lugar ou situação pode referir-se a um espaço físico ou pode referir-se a uma situação que reflete status social. [...\} por exemplo ter acesso ao ensino superior.
\end{abstract}

Miranda (2006, p. 7) afirma que "o Brasil está em um momento, no qual a democratização do acesso e permanência na universidade de grupos socialmente desfavorecidos está obtendo maior espaço." Porém, ainda faz-se necessário que as legislações e conceitos sobre a acessibilidade sejam inseridos de fato no ambiente educacional de forma que possam ser sentidas por aqueles que dela necessitam e assim possam fazer parte do plano de desenvolvimento educacional e de suas avaliações institucionais.

De acordo com Andriola (2003 b) \& Belloni (1999) apud Andriolla (2004, p.34): "Compreendemos a avaliação institucional como um processo que permite a reflexão sobre a realidade estudada e que nos exige, a todos os atores implicados, o compromisso com o conhecimento e com o consequente aprimoramento dessa mesma realidade".

Assim, para avaliar as estratégias de acessibilidades desenvolvidas pelo IFCE, faz-se necessário que os atores inseridos no âmbito educacional possam ter ciência da missão da instituição, do contexto onde esta inserido e de sua trajetória histórica para compreender em paralelo os processos da inclusão social de $\mathrm{PcD}$, desenvolver e/ou avaliar estratégias a serem desenvolvidas em busca da eliminação de barreiras atitudinais e pedagógicas. 


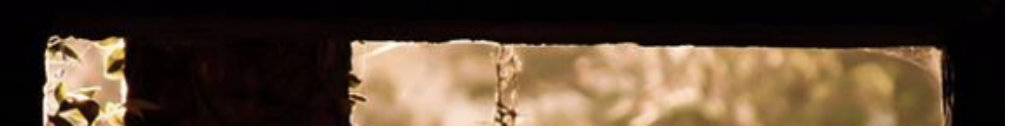

Dentro deste contexto surgi o termo Tecnologia Assistiva utilizado para identificar todo o arsenal de recursos e serviços que contribuem para proporcionar ou ampliar habilidades funcionais de pessoas com deficiência e consequentemente promover vida independente e inclusão. Segundo Rocha e Miranda (2009):

[...] enquanto os alunos com deficiência física têm como critério para sua acessibilidade a existência de espaços físicos adaptados (rampas, corrimões, trincos de porta, banheiros, bebedouros, telefones públicos, etc.), em relação à deficiência visual, a acessibilidade depende de materiais como computadores com softwares adequados, impressoras Braille, etc. No concernente a surdez, o aluno deve ter direito a um intérprete em Língua Brasileira de sinais - LIBRAS - por exemplo.

A implantação da proposta da Educação Inclusiva na Educação Profissional e Tecnológica exige um acompanhamento sistemático dos desdobramentos de suas ações praticadas cotidianamente verificando as possibilidades de transformações que podem surgir aliadas a um processo de avaliação institucional que congregue as funções formativas (conhecer e aperfeiçoar) e somativa (certificar, selecionar).

Para Marilena Chauí (2003, p. 6),

[...] se quisermos tomar a universidade pública por uma nova perspectiva, precisamos começar exigindo, antes de tudo, que o Estado não tome a educação pelo prisma do gasto público e sim como investimento social e político, o que só é possível se a educação for considerada um direito e não um privilégio, nem um serviço.

\section{METODOLOGIA}

$\mathrm{Na}$ pesquisa, utilizou-se a abordagem qualitativa por acreditar que os sujeitos pesquisados são parte integrante do conhecimento. Esses apresentam um saber prático da realidade, da experiência cotidiana. Segundo Chizzoti (2006, p. 83):

(...)a abordagem qualitativa parte do fundamento de que há uma relação dinâmica entre o mundo real e o sujeito, uma interdependência viva entre o sujeito e o objeto, um vínculo indissociável entre o mundo objetivo e a subjetividade do sujeito. (Chizzoti, 2006, p.79)

Porém, não se pode descartar a importância dos dados quantitativos porque são através deles que mensuramos as ações desenvolvidas, os números reais de pessoas com 


\section{EDUCAÇÃO, ARTES E INCLUSÃO}

necessidades educacionais específicas nos campi, catalogamos informações para assim desenvolver as possíveis análises críticas.

Por este motivo utilizou-se a pesquisa quali-quantitativa para realizar uma análise dos documentos já produzidos, dos dados institucionais, além de, uma descrição e análise dos processos de trabalho do NAPNE do IFCE-campus Limoeiro do Norte, no período de março de 2014 a março de 2015.

Nesse período, o Campus Limoeiro do Norte tinha 06 discentes com deficiência, sendo estes: Quanto à deficiência: Um (01) com deficiência física (amputação de membro inferior); Um (01) com baixa visão; Uma (01) surda, Três (03) com deficiência auditiva. Quanto ao sexo: 03 femininos e 03 masculinos. Quanto à idade: discentes entre a faixa etária de 22 a 33 anos. Quanto ao curso: Superior (Agronomia, Nutrição e Mecatrônica), Técnico (Panificação). Quanto ao semestre: discentes no $1^{\circ}, 4^{\circ}, 6^{\circ}, 7^{\circ}$ e $10^{\circ}$ semestre.

Para o desenvolvimento desse estudo, os procedimentos teórico-metodológicos utilizados foram: pesquisa bibliográfica, buscando conhecer as publicações pertinentes e aprofundar o conhecimento; e, pesquisa-ação averiguando as ações de acessibilidade desenvolvidas para o ingresso e a permanência de discentes com deficiência no IFCE/campus Limoeiro do Norte, colaborando com a realização de ações em busca do melhoramento das atividades de Educação Inclusiva.

A realização da pesquisa bibliográfica utilizou como categorias de estudo: Educação Inclusiva, Educação Profissional e Tecnológica e Acessibilidade. Os autores de referência na pesquisa bibliográfica foram: Mazzote (1999); Sassaki (1997); Rocha e Miranda (2009); e, Freire (1999).

Referente à pesquisa-ação analisou-se as seguintes ações de acessibilidade desenvolvidas pelo NAPNE:

1) Palestras e Oficinas de sensibilização sobre a temática da Educação Inclusiva incluindo as seguintes etapas. $1^{\text {a }}$ etapa: Palestra sobre divulgação do Centro de Treinamento Cãoguia; $2^{\mathrm{a}}$ etapa: Oficina sobre tecnologia assistiva com exibição de protótipo construído para pessoas com deficiência visual; $3^{\text {a }}$ etapa: Oficina de vivência inclusiva apresentando conceitos e desenvolvendo práticas sobre barreiras arquitetônicas em espaços públicos.

2) Elaboração de tutoriais de orientações e adaptações didática-pedagógica;

3) Desenvolvimento do Projeto de Monitorias Inclusivas, com o objetivo de dar suporte aos discentes com deficiência.

4) Levantamento de acessibilidade arquitetônica do campus 


\section{RESULTADOS E DISCUSSÕES}

Com resultado deste estudo verificou-se que, a partir das ações desenvolvidas pela equipe interdisciplinar do NAPNE, estudos e planejamentos de eventos de sensibilização foram realizados junto à comunidade acadêmica e comunidade externa para a promoção de práticas pedagógica que fortaleceram o processo da Educação Inclusiva.

Durante um ano de atividades desenvolvidas pelo NAPNE, constatou-se que ações de extensão promoveram práticas integradoras entre servidores, discentes e comunidade externa permitindo uma discussão da temática da educação inclusiva dentro e fora do ambiente de sala de aula.

Referente ao primeiro tópico de análise deste estudo, isto é, Palestras e Oficinas de sensibilização sobre a temática da Educação Inclusiva, verifica-se que ações de caráter inclusivo no ambiente educacional são primordiais para a construção de estratégias que venham eliminar barreiras atitudinais e desenvolver uma cultura inclusiva que pode se desdobrar a outros espaços sociais. No primeiro evento contamos com a participação de 10 pessoas, no segundo 25 pessoas e no terceiro 34. Além de verificarmos o aumento no número de participantes, observou-se que a continuidade das ações promoveu uma integração com a sociedade civil, isto é, o envolvimento com lideranças comunitárias e outros profissionais que trabalham com a temática da inclusão.

Conforme defende Freire (1999), a educação não está relacionada exclusivamente ao ensino de conteúdos, isto representa uma compreensão estreita do que é aprender. As experiências informais, o aprendizado em casa e na rua, também são carregadas de transferências de aprendizados. Porém, o ambiente escolar carrega uma forte imagem em relação a esta transferência de conhecimento. Assim, utilizar este ambiente para desenvolver ações multidisciplinares e interinstitucionais discutindo o respeito à diversidade, a acessibilidade, possibilita o despertar da construção de novos conhecimentos, da aceitação do diferente, sem indiferença. Segundo Freire (1999:49): "Há uma pedagogicidade indiscutível na materialidade do espaço".

Referente ao segundo ponto analisado nesta pesquisa (Elaboração de tutoriais de orientações e adaptações didática-pedagógica), inicialmente foi feito um cadastro dos discentes com deficiência com o objetivo de identificar a situação específica de cada aluno, 


\section{EDUCAÇÃO, ARTES E INCLUSÃO}

através de uma escuta qualificada, e elaborar documento de orientações didáticopedagógicas que oferecesse ao docente um suporte para adaptações necessárias que viessem oportunizar uma melhor aprendizagem ao discente. Segue, na Tabela 02, as descrições das adaptações sugeridas.

\begin{tabular}{lll}
\hline Tipo de Deficiência & \multicolumn{2}{c}{ Tutorial } \\
\hline Def. Físico & $\begin{array}{l}\text { Não foi sistematizada nenhuma adaptação didático-pedagógica, mas } \\
\text { adquirido equipamentos e realizado pesquisa em relação às barreiras } \\
\text { arquitetônicas no campus. }\end{array}$
\end{tabular}

Def. Auditivo e Disponibilização pelos docentes de lista de exercício e nota de aula; avisos Surdo escritos sobre datas de prova, recuperação de aula, páginas a serem estudas, etc; material impresso com antecedência; horário de atendimento individual; disponibilização de intérprete em libras.

Baixa Visão Disponibilização pelos docentes de lista de exercícios; adaptação de material de aula e avaliações coma criação de tutorial de adaptação individualizado para alunos com baixa visão, disponibilização dos materiais didáticos digitalizado com antecedência.

Tabela 02: Descrição das orientações e adaptações didática-pedagógica. Fonte: Pesquisa local, 2015.

É válido ressaltar que para concretização desta pesquisa houve a participação da equipe de pesquisadores nos encontros pedagógicos, eventos educativos com todo corpo de discentes e reuniões sistemáticas realizadas pela equipe gestora do NAPNE para que assim existisse uma aproximação das propostas de atuação.

Em relação ao desenvolvimento de Projeto de Monitorias Inclusivas ${ }^{5}$, verificou-se que houve uma melhoria no desempenho escolar do discente com deficiência através de análise de dados acadêmicos do aluno (histórico escolar), o qual ratificou a aprovação de $80 \%$ dos discentes no semestre corrente a realização dos acompanhamentos.

Porém, é válido destacar que a evasão de uma (01) discente surda acompanhada pelo NAPNE, leva a observar que a cultura inclusiva se torna urgente, pois segundo a fala da própria discente, a mesma se desligou do curso porque se achava sozinha, diferente dos demais. Isso requer uma avaliação da postura dos ouvintes no ambiente educação, assim como da abertura do próprio deficiente para viver novos desafios. De acordo com Bragança $(2009$, p. 22):

Uma sociedade só será inclusiva quando qualquer cidadão for respeitado e valorizado por sua pessoa e não por seu físico ou condição social. No entanto, para podermos realmente caminhar nessa direção, devemos primeiro combater os tabus e os preconceitos mais escondidos.

\footnotetext{
${ }^{5}$ Projeto criado com o objetivo de propiciar ao discente com deficiência acompanhado pelo NAPNE um suporte em relação ao ensino-aprendizado no semestre matriculado. O aluno bolsista faz um reforço escolar, discutindo dúvidas e auxiliando nos estudos do conteúdo apresentado em sala de aula.
} 
Em relação à quarta atividade avaliada nesta pesquisa referente às barreiras arquitetônicas existentes no campus teve-se como suporte a Normas Brasileiras de Regulamentação (NBR 9050:2004) e o Guia de Acessibilidade (2009) identificando-se as seguintes questões:

-Piso Tátil: O IFCE/campus Limoeiro o Norte possui apenas o piso tátil de alerta em um dos blocos e, mesmo assim, ainda podem ser verificados erros de sinalização. Além disso, não há piso tátil de alerta para sinalização de mobiliários suspensos. -Escada: não há sinalização nas escadas antes do primeiro degrau e depois do último para avisar da mudança de nível. Não há sinalização de cor contrastante junto às bordas de todos os degraus, de forma a identifica os limites da escada. -Rampas: as rampas de acessibilidade possuem largura adequada, mas não há a presença de piso tátil de alerta e piso tátil direcional demonstrando outro nível de piso e apresentam inclinações acima do que é recomendado, apresentando valores como de $14 \%$ a $24,5 \%$ do recomendado. - Bibliotecas: os corredores de acesso aos livros de pesquisa variam de $1,10 \mathrm{~m}$ a $0,70 \mathrm{~m}$ segundo as normas a distância não pode ser inferior a $0,96 \mathrm{~m}$. Em relação à altura do balcão de atendimento este está acima dos padrões e não apresenta área de deslocamento ou encaixe para PcD ou mobilidade reduzida. -Bebedouros: não há barras de apoio, a altura de acesso à torneira e/ou bica variam não obedecendo ao padrão de $0,73 \mathrm{~cm}$. - Portas: As portas estão adequadas com $1,73 \mathrm{~cm}$, porém não existe informações tátil nas mesmas ou em batentes próximos; a grande maioria das maçanetas encontradas na instituição de ensino não estão adequadas quanto ao sentido e encontram-se cerca de $0,06 \mathrm{~m}$ abaixo do adequado para pessoas com necessidades especiais; As portas não possuem material resistente a impactos, bem como a não presença de piso direcional e piso tátil. - Lavatórios: No ambiente da convivência há uma pia, cuja mesma mede $0,90 \mathrm{~cm}$, sendo esta $0,10 \mathrm{~cm}$ acima do proposto pelo Guia de Acessibilidade; No balcão utilizado para a distribuição do lanche, o mesmo possui $84 \mathrm{~cm}$ de altura, onde este se apresenta de acordo com a norma estabelecida; Os outros lavatórios localizados nos banheiros estão de acordo com as normas exigidas no Desenho Universal.

Considerando este público, o NAPNE fez a aquisição de alguns equipamentos e nossa pesquisa catalogou tais produtos fazendo uma descrição dos itens e sua função, conforme segue adiante: 


\begin{tabular}{|c|c|c|}
\hline Item & Produto & Utilização \\
\hline 01 & Tablet Galaxy & Equipamento utilizado para auxiliar discente com baixa visão \\
\hline 02 & Máquina de escrever em braile & $\begin{array}{l}\text { Equipamento utilizado para transcrever material didático- } \\
\text { pedagógico em braille }\end{array}$ \\
\hline 03 & Scanner com voz & Equipamento que converte material impresso em áudio. \\
\hline 04 & $\begin{array}{l}\text { Multi plano ou multiuso } \\
\text { inclusivo kit A com maleta. }\end{array}$ & $\begin{array}{c}\text { Ferramenta para desenvolver a lógica matemática em alunos dom } \\
\text { deficiência visual. }\end{array}$ \\
\hline 05 & Lupa eletrônica & Equipamento para ampliação de textos e imagens em computador. \\
\hline 06 & Caixa de som multi laser & $\begin{array}{l}\text { Equipamento para ampliação de audio para discente com baixa } \\
\text { audição }\end{array}$ \\
\hline 07 & Uma cadeira de rodas & $\begin{array}{c}\text { Equipamento para auxilia na mobilidade de pessoas com } \\
\text { deficência física }\end{array}$ \\
\hline 08 & Traves para Goalball & Jogo/brinquedo pedagógico \\
\hline 09 & Kit 06 lupas manuais & $\begin{array}{l}\text { Equipamento utilizado para auxiliar discente com baixa visão com } \\
\text { ampliação de texto impresso }\end{array}$ \\
\hline
\end{tabular}

Tabela 03: Materiais comprados pelo NAPNE. Fonte: Pesquisa de campo

\section{CONSIDERAÇÕES FINAIS}

Compreendendo que a pesquisa condensa informações de grande importância para disseminação da temática de Educação Inclusiva tomar posse destas informações e difundilas possibilita uma melhor compreensão da política de inclusão, assim como, de seus entraves e limites dentro do espaço educacional.

Além disso, ao verificar e sistematizar as ações realizadas pela equipe do NAPNE no campus Limoeiro do Norte é criado um instrumento que unifica seus dados e possibilita esclarecimentos e disseminação da educação inclusiva ao corpo de docentes, discentes e técnicos administrativos, considerando que será feito a devolutiva do resultado deste trabalho.

Depois de dois anos da criação do NAPNE no IFCE Campus Limoeiro do Norte, pode-se concluir que alguns frutos já foram colhidos, tais como: o acompanhamento de alunos com deficiência, a participação e promoção de eventos para informação e sensibilização da comunidade acadêmica (estudantes, professores, técnico-administrativos, etc), visando expandir o tema, ações que já repercutem dentro do Campus e encorajam discentes a se identificarem com suas deficiências, ajudando a superar seus limites e garantir o acesso e permanência no ensino técnico e tecnológico no Campus de Limoeiro do Norte.

Como resultado do trabalho desenvolvido no NAPNE/Campus Limoeiro do Norte, pode-se verificar: aumento da participação da comunidade em eventos promovidos com a 


\section{EDUCAÇÃO, ARTES E INCLUSÃO}

\section{6}

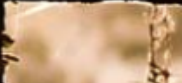

temática da educação inclusiva (considerando que na terceira palestra triplicou o número de participantes de acordo com as frequências assinadas); melhoria no desempenho escolar de discentes com deficiência ( $80 \%$ de aprovação no semestre); viabilidade da construção de estratégias para a garantia do acesso e a permanência de PcD no campus (elaboração de fluxograma com equipe de profissionais para facilitar acolhimento e permanência); e, aproximação com sociedade civil com estabelecimento de parcerias.

Desenvolver práticas pedagógicas integradoras exige de todos os profissionais do ambiente educacional um conhecimento do seu principal objeto de trabalho - o discente para que assim se possa desenvolver competências, habilidades e tecnologias que venham favorecer o processo de inclusão de forma participativa e integradora.

De acordo com Freire (1999, p. 90) o processo de mudança se inicia no diálogo "em que se vai desafiando o grupo popular a pensar sua história social como a experiência igualmente social de seus membros, vai revelando a necessidade de superar certos saberes que, desnudados, vão mostrando sua "incompetência" para explicar os fatos". Os saberes se constroem e estão a todo instante em processo de mudança quando educadores se permitem a descobrir com o outro um novo aprendizado, sendo assim educador e educando ao mesmo tempo.

Desta forma, torna-se necessário que estratégias de acessibilidade sejam desenvolvidas constantemente através de formação de professores, realização de cursos de qualificação para adaptações didáticas e pedagógicas, flexibilidade curricular, eventos de sensibilização sobre inclusão de $\mathrm{PcD}$, além de ser destinação de recursos financeiros para eliminação de barreira arquitetônicas e criação de espaços inclusivos.

\section{REFERÊNCIAS}

ASSOCIAÇÃO BRASILEIRA DE NORMAS E TÉCNICAS- ABNT NBR 9050. Acessibilidade a edificações, mobiliário, espaços e equipamentos urbanos. Segunda edição: 2004, 97 páginas.

ANDRIOLA, W. B. Avaliação institucional na Universidade Federal do Ceará (UFC): organização de sistema de dados e indicadores da qualidade institucional. Sumários Correntes Periódicos Online (Unicamp), Campinas, v. 9, n.4, p. 33-54, 2004.

BRASIL, Constituição de 88. Constituição da Republica Federativa do Brasil. Brasília, DF: Senado Federal. 


\section{EDUCAÇÃO, ARTES E INCLUSÃO}

\section{(5)}

Lei $\mathrm{n}^{\circ}$ 9.394/96 de 20 de dezembro de 1996. Estabelece as Diretrizes e Bases da educação nacional. Diário Oficial da República Federativa do Brasil, Brasília, DF, 31 de dez.1996.

Ministério da Educação. Política Nacional de Educação Especial na perspectiva da Educação Inclusiva, Brasília, 2008.

. [Plano Nacional de Educação (PNE)]. Plano Nacional de Educação 20142024 [recurso eletrônico] : Lei $\mathrm{n}^{\mathrm{o}} 13.005$, de 25 de junho de 2014, que aprova o Plano Nacional de Educação (PNE) e dá outras providências. - Brasília: Câmara dos Deputados, Edições Câmara, 2014. 86 p. - (Série legislação ; n. 125). Acessado no site http://www.observatoriodopne.org.br/uploads/reference/file/439/documentoreferencia.pdf. Em dezembro de 2015.

Decreto $\mathrm{n}^{\circ} 3.298$ de 1999 que regulamenta a Lei $\mathrm{n}^{\mathrm{o}} 7.853$, de 24 de outubro de 1989, dispõe sobre a Política Nacional para a Integração da Pessoa Portadora de Deficiência, consolida as normas de proteção, e dá outras providências. Acessado em http://www.planalto.gov.br/ccivil 03/decreto/D3298.htm. Em dezembro de 2015.

Decreto de $n^{\text {o }} 6.949$ de 25 de agosto de 2009. Promulga a Convenção Internacional sobre os Direitos das Pessoas com Deficiência e seu Protocolo Facultativo, assinados em Nova York, em 30 de março de 2007. Acessado em 15 de maio de 2015 no site http://www.planalto.gov.br/ccivil_03/ato20072010/2009/decreto/d6949.htm

Ministério da Educação. Secretaria de Educação Especial. Marcos Políticos Legais da Educação Especial na Perspectiva da Educação Inclusiva/ Secretaria de Educação Especial. Brasília: Secretaria de Educação Espacial, -2010. 73p.

. Ministério da Educação. Secretaria de Educação Tecnológica. Coordenação de Educação Profissional e Tecnológica Inclusiva. Ação TEC NEP, Dez anos depois....Censinho 2011. Brasília/DF: julho de 2011.

Ministério da Educação. Numero de matriculas de pessoas com deficiência cresce no Brasil. Portal do MEC, $1^{\circ}$ de julho de 2015. Entrevista com Walter Borges dos Santos, coordenador-geral de política de acessibilidade na escola da Secretaria de Educação Continuada, Alfabetização, Diversidade e Inclusão (Secadi) do Ministério da Educação. Acessado em outubro de 2015, no site http://portal.mec.gov.br/component/content/index.php?option=com_content\&view $=$ article \&id=21439:numero-de-matriculas-de-pessoas-com-deficiencia-cresce-nobrasil\&catid $=202 \&$ Itemid $=86$

BRAGANÇA, Soraya; PARKER, Marcelo. Igualdade nas diferenças: os significados do "ser diferente" e suas repercussões na sociedade. Universidade Estadual do Rio Grande do Sul, Porto Alegre, UERGS, 2009. 


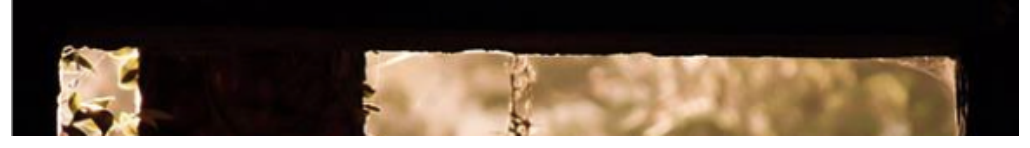

CENSO DEMOGRÁFICO 2010. Características gerais da população, religião e pessoa com deficiência: resultados do universo. Disponível em http://www.ibge.gov.br/home/estatistica/populacao/censo2010/caracteristicas_da_populaca o/default_caracteristicas da populacao.shtm

CHAUI, Marilena. A universidade pública sob nova perspectiva. Rev. Bras. Educ., Rio de Janeiro, n. 24, set./dez. 2003. Acessado em 06 de maio de 2015. Disponível em: $<$ http://www.scielo.br/scielo.php?script=sci_arttext\&pid=S141324782003000300002\&lng $=$ en\&nrm $=$ iso $>$.

CHIZZOTTI, Antônio. Pesquisa em ciências humanas e sociais. 8 ed. São Paulo: Cortez, 2006.

FIGUEIRA, Emílio. Caminhando no Silêncio - Uma introdução à Trajetória das Pessoas com Deficiência na História do Brasil - Giz Editora, São Paulo, 2008.

FREIRE, Paulo. Pedagogia da Autonomia. Saberes Necessários à Prática Educativa. São Paulo: Paz e Terra, 1999.

GLAT, Rosana et all. Inclusão de Pessoas com Deficiência e outras necessidades especiais na escola e no trabalho. Acessado em http://www.sjp.pr.gov.br/wpcontent/uploads/2013/04/CIEE texto_GLAT_et_all_versao final_agosto_2011.pdf

MAZZOTTA, José Marcos da Silveira. Educação especial no Brasil: história e políticas públicas. 5. ed. São Paulo: Cortez, 2005.

MAZZOTTA, Marcos J. S. Educação especial no Brasil: história e políticas públicas/ Marcos J.S. Mazzotta. - 6. Ed.- São Paulo: Cortez, 2011.

MANZINI, José Eduardo. Acessibilidade: um aporte na legislação para o aprofundamento do tema na área da educação. In BAPTISTA, Claudio Roberto; CAIADO, Katia Regina Moreno; JESUS, Denise Meyrelles de et alii(org.). Educação Especial: diálogo e pluralidade. Porto Alegre, RS: Editora Mediação, 2008.

MIRANDA. Theresinha Guimarães. A inclusão de pessoas com deficiência na universidade. SEMINÁRIO DE PESQUISA EM EDUCAÇÃO ESPECIAL, 2., 2006. Vitória, ES. Anais...Vitória, ES: UFES, 2006.

ROCHA, Telma Brito; MIRANDA, Theresinha Guimaraes. A inclusão de alunos com deficiência no Ensino Superior: uma análise de seu acesso e permanência. In: Educação inclusiva, deficiência e contexto social: questões contemporâneas/ Féliz Díaz, Miguel Bordas, Nelma Galvão, Theresinha Miranda, organizadores; autores, Elias Souza dos Santos... [et al.]. - Salvador: EDUFBA, 2009.354p.

SASSAKI, Romeu Kazumi. Inclusão: construindo uma sociedade para todos. Rio de Janeiro, 1997.176

VIEIRA, Sheila Rodrigues; BONDEZAN, Andréia Nakamura. A Pessoa com deficiência: História e Legislação. $5^{\circ}$ Congresso Internacional de Educação, Pesquisa E Gestão. Tema - 


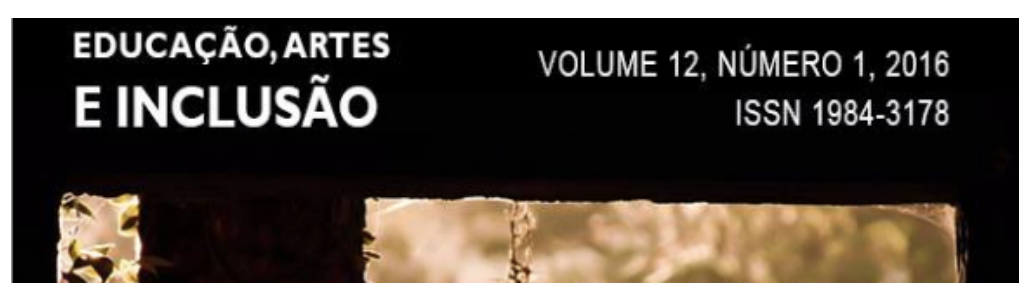

Educação Inclusiva: Desafios e Possibilidades, 2013. Acessado em janeiro de 2016 no site: www.isapg.com.br $/ 2013 /$ ciepg $/$ down.php? id $=33 \& q=1$.

Recebido em 13 de fevereiro de 2016 Aprovado em 28 de março de 2016 